\title{
Decoupling paradigm of push-pull theory of oscillation in the FMCG industry
}

\author{
T.P. Mbhele* \\ University of KwaZulu Natal (Westville Campus), School of Management, IT \& Governance, \\ Private Bag X54001, Durban 4000, South Africa \\ *To whom all correspondence should be addressed \\ mbhelet@ukzn.ac.za
}

\begin{abstract}
The amplification of demand order variability germinates from distorted demand information upstream while sometimes reacting to demand-driven inventory positioning influenced by the custodians of downstream information. This study uses factor analysis to tentatively develop a supply chain model to enhance the competence of supply chain performance in terms of responsiveness, connectivity and agility. The results of the analysis indicate that the magnitude of control on the bullwhip effect and access to economic information on demand orders in the supply chain network are associated with the modelling of the push-pull theory of oscillation on three mirror dimensions of supply chain interrelationships (inventory positioning, information sharing and electronically-enabled supply chain systems). The findings provide the perspective on managing amplification in consumer demand order variability upstream in the supply chain network while enhancing the overall efficiency of supply chain performance. This article provides insight into the use of innovative strategies and modern technology to enhance supply chain visibility through integrated systems networks.
\end{abstract}

\section{Introduction}

In South Africa's rapidly changing consumer landscape, fast moving consumer goods (FMCG) retail outlets as well as suppliers are gradually acknowledging the need for the efficient strategic diffusion of electronic information through integrated supply chain information technology (SCIT). According to Sorescu, Frambach, Singh, Rangaswamy and Bridges (2011:7), retail business model (RBM) innovation is defined as "a change beyond current practice in one or more elements of a retailing business model (retailing format, activities and governance) and their interdependencies, thereby modifying the retailer's organising logic for value creation and appropriation". If the business model represents the firm's distinctive logic for value creation and appropriation (Teece, 2010; Zott \& Amit 2010), the strategy epitomises a central, integrated, externally-oriented concept of how the business will achieve these essential strategic objectives (Hambrick \& Fredrickson, 2005; Gambardella \& McGahan, 2010).

Modern global business environments exhort retailers to constantly look beyond organisational boundaries to evaluate and integrate the resources and capabilities of their suppliers and customers. The multi-directional retail practices leverage upstream and downstream relationships in the supply chain network. Ganesan, George, Jap, Palmatier and Weitz (2009:84) recommend "the propensity towards global sourcing practices and the nature of interfirm ties between retailers and the organisational partners for better product and process innovations". To a certain extent, these approaches will create superior value and a competitive advantage that companies might sustain over time. Attaining competitive advantage requires the creation of an integrated system that has a unique advantage over competitors to create customer value in an efficient and sustainable way. Heizer and Render (2011:68) advocate "competitive advantage in terms of competing on response strategy (pullbased system) where a set of values relate to rapid, flexible, and reliable performance". This study aims, firstly, to analyse the challenges raised by the push- and pull-based oscillation effect from the perspective of electronicallyenabled supply chain management (e-SCM) systems, information sharing, inventory positioning and global optimisation strategies in the FMCG industry. The second objective is to establish the discrete dimensions in the pattern of interrelationships among the bullwhip effect challenges together with mitigation strategies for reduced underlying sets of integrated and synchronised dimensions.

\section{Conceptual view}

\section{The phenomenon of bullwhip effect}

Companies operating in different markets have observed a phenomenon known as bullwhip effect, in which order vacillations increase as orders move upstream. Apart from observations, Ouyang (2007:1107) describes the bullwhip effect as "a phenomenon in supply chain operations where the fluctuations in the order sequence are usually greater upstream than downstream of a chain". Chopra and Meindl (2007:525) associate the phenomenon with the influence on profitability throughout the network with subsequent costly inventory levels and positioning. A firm's ability to establish and retain satisfactory customer relationships requires an understanding of buying behaviour. This refers to the decision processes and acts of those who buy and use products for personal or household use, rather than for business purposes (Pride \& Ferrell, 2009:171). The sustainable level of profitability in the supply chain requires 
focus on positioning and better integration of organisations. In this way, all participants in the network seem to benefit from synchronised decision-making processes based on the underlying high levels of trust, competent collaboration, and active communication.

Recognising the realities of paradigm shift in supply chain management, supply chains versus supply chains as a competition genre creates intensity in integrating more business activities across the internal and external supply chain processes. Eventually, this competitive trend serves an essential purpose of adding value for trading supply chain partners and customers. Contrarily, Miragliotta (2006:366) highlights the dearth of supply chain integration in referring to bullwhip effect as "a supply chain phenomenon revealed by a distortion (variability amplification and- /or rogue seasonality) of the demand signal as it is transmitted upstream from retailers to suppliers". Demand vacillations prevail in multiple echelon-stages as orders move from underlying push-based oscillation to the upstream site of the network. $\mathrm{Wu}$ and Katok (2006:839-850) attempt to summerise the bullwhip effect, in terms of, "the observation that the variability of orders in supply chains increases as one moves closer to the source of production". These definitions indicate that the pull-based oscillation network chain structure and linkage is the result of value-creating systems and demand-driven orders emanating from integrated multiple nodes. This study interprets the dynamics of supply chain networks as a complex web of interconnected nodes (representing entities or facilities such as suppliers, distributors, factories and warehouses) and links (representing the means by which the nodes are connected on supply chain mapping flows).

\section{Dynamics of supply chain management}

The oscillation effect on distorted order information traveling up stream indicates amplified consumer demand order variability (DoV) and results in diluted accountability, and fosters distrust of information and a bloated inventory level. The analysis indicates that decentralised demand information can significantly increase the variability while centralised demand information can significantly reduce, but will not eliminate, the bullwhip effect (Simchi-Levi, Kaminsky \& Simchi-Levi, 2008; Snyder \& Shen, 2011).The integration of the development chain, demand chain, distribution chain and supply chain through information sharing mechanisms and electronically-enabled supply chain management at multi-level echelons has the propensity to enhance customer-centric business strategies and ameliorate the pernicious problem of the bullwhip effect. These chain networks reflect supply chain architecture that involves a sequence of value-added processes with an attempt to match supply and demand, while the demand chain focuses on creating and managing the quantities of one or more products that can be served by a supply chain (Schroeder, 2008). In the same perspective, Coyle, Langley Jr, Novack, and Gibson (2013:16) view supply chain management as "a pipeline or conduit for the efficient and effective flow of products/materials, services, information and financials from the supplier's suppliers through the various intermediate organisations out to the customer's customers or the system of connected networks between original vendors and the ultimate final consumer". This study alludes to the interpretation of supply chain management in the same light as the broad and comprehensive synchronisation of flows with integrated-based activities and extended enterprises. This advocates an improvement in supply chain performance that is achieved by means of a schematic network of interrelationships and interconnectivity between its elements in order to minimise system-wide costs while satisfying service level requirements. Integrated electronically-enabled supply chain management (e-SCM) systems and synchronised decision-making responsibility across extended enterprises can be expected to respond directly to genuine customer demand with an anti-oscillator effect.

\section{Theoretical framework}

\section{Diffusion of electronic supply chain management systems}

This study posits that investment in infrastructural information technology (IT) projects and remodeling electronic supply chain procedures will enable suppliers to cooperate and collaboratively espouse e-SCM diffusion. $\mathrm{Wu}$ and Chuang (2009:302) concur with Lin and Huang (2012:164) in defining e-SCM systems diffusion as "a process from internal diffusion among functional units within an organisation to external diffusion across interorganisational trading partners when e-SCM becomes an integral part of the value activities". According to Hornor (2008:1), the theory of diffusion of innovation dates back to 1903, when the French sociologist, Gabriel Tarde designed the original S-shaped curve. The S-shaped curve is important because most innovations have an $\mathrm{S}$-shaped rate of adoption and it is used widely in the application of global technologies. The diffusion process explains and predicts the period of adoption of new innovations in the marketplace based on the underlying concepts and theories of communication and interaction among supply chain members (Rangaswamy \& Gupta, 1999; Shane, 2014). Rogers (1962) cited in Hornor (2008:1) defines diffusion as "a process by which an innovation is communicated through certain channels over time among members of a social system". This process is a set of interrelated units that are engaged in an effective collaboration to accomplish a mutual economic goal. Essentially, the theory of diffusion of innovation is distinguished by individual characteristics of five stages of adoption, such as awareness, interest, evaluation, trialability and observability (Rogers, 1962; Horner, 2008); whereas more recently, Tidd and Bessant (2011:355-359) identify the five characteristics of innovation as being relative advantage, compatibility, complexity, trialability and observability. 


\section{Diffusion and capability theories}

Diffusion of innovation (DOI) is predominantly based on the characteristics of the technology and the users' perceptions of the innovation (Rogers, 2003). DOI is influenced by leadership attitude toward change, interconnectedness and system openness within the context of technology and top management support within the organisational context (Oliveira, Thomas \& Espadanal, 2014:497). In similar vein, Yeh (2005:327-335) performs the correlation of factors in an e-SCM relationship where "resource dependence, trust and relationship commitment are positively related to the continuity of the cooperative electronic supply chain relationship; and risk perception is negatively related to the continuity of the cooperative electronic relationship". The dynamic capability theory (DCT) elaborates more on how organisations and supply chains can integrate, build or deploy and reconfigure their internal resources and external competencies in a changing environment (Teece, Pisano \& Shuen, 1997; Newbert, 2007). The dynamic capabilities are critical for performance in technology-based environments as they determine the clockspeed (Teece, 2007), and e-supply chain integration needs to be embedded in the strategies and goals of partnering organisations as supply chain networks (Rajaguru \& Matanda, 2013:620). Despite these empirical results, Oliveira \& Martins (2010) and Ifinedo (2011) maintain that technological innovations benefit an organisation's members in terms of real-time communication, decreased inventory and increased service levels. Lin and Huang (2012:162) underpin the theoretical perspective that "perceived benefits, knowledge management capability, and trading partner influence are important factors shaping e-SCM systems diffusion".

Systems diffusion allows quasi-real-time information sharing on inventory position and product development among trading supply chain partners, and thus generates a synergic effect (Yao, Palmer \& Dresner, 2007:884). According to the organisational information processing theory (OIPT) an organisation's information processing capabilities must be aligned with its information needs whereby an organisation must be able to gather, interpret, synthesise, and coordinate information across the organisation (Burns \& Wholey, 1993:106-138). Frohlich and Westbrook (2001) and Schoenherr and Swink (2012) assert that visibility can be distinguished from external supply chain integration that addressed more general information sharing and collaborative processes. According Williams, Roh, Tokar and Swink (2013:543) a strategy for achieving supply chain responsiveness requires a dualpronged approach that aligns increased visibility with extensive information processing capabilities from internal integration. Although organisations are confronted by a number of technological challenges, including the lack of employee training and education, there is a need to understand the benefits and goals of e-SCM as well as its poor implementation (Migiro \& Ambe, 2008). The e-SCM systems diffusion accelerates e-SCM development and provides new ways to integrate web-based technologies with core businesses that affect both cross-functional (inside) and extended cross-enterprise (outside) value chain networks for business transformation (Wu \& Chuang, 2009; Tarofder, Marthandan \& Haque 2010; Lin \& Huang, 2012). Cai and $\mathrm{Du}$ (2009:709) recommend that the strategy of risk pooling is designed to "bring about demand aggregation across locations or time, in order to reduce the variability which is measured by either the standard deviation or the coefficient of variation".

\section{Oscillated push and pull theory}

The hybrid system of push-pull boundary occurs at the point in time that the firm switches from managing the supply chain using one strategy (push system), to managing it, using a different strategy (pull system) (Simchi-Levi et al., 2008). In interpreting the system, Bowersox, Closs, Cooper and Bowersox (2013:12) interpret an anticipatory business model as a push system (produces a product based on a market forecast) while the responsive business model is associated with a pull system (relies on timing and agility) that focuses on reducing forecast reliance and improving joint planning and real-time information exchange. The decoupling point also acts as a strategic point for buffer stock, and its position changes depending on the variability in demand and product mix (Mason-Jones, Naylor \& Towill, 2000). An increase in product mix and fluctuating volume would force the decoupling point to move upstream, making the supply chain system more agile in order to ameliorate the magnified oscillations upstream. The use of supply chain IT to share data between buyers and suppliers is valuecreating as the virtual supply chain is information-based (resulting in pull-based oscillation) rather than inventorybased (resulting in push-based oscillation). Machuca and Barajas (2004:209) describe the behavioural patterns as oscillation, where orders and inventory demonstrate large amplitude-fluctuation nodes in the supply chain. In a closedloop supply chain (forward and reverse supply chain activities for the entire life cycle of the product), oscillation arises from the combination of time delays in negative feedback and the failure of the decision-maker to take time delays into account (Ding \& Gan, 2009:343).

From the perspective of the pull theory of oscillation on the supply chain network along the production, consumption and replenishment cycles, consumer DoV emphasises, firstly, a demand-driven supply network that builds supply chains in response to demand signals through alignment (create shared incentives); secondly, agility to respond quickly to short-term change; and finally, adaptability in terms of adjusting the design of the supply chain to create sustainable competitive advantage. Christopher (2011:103) stresses that "supply chain partners can only make full use of quasi-real-time shared information through process alignment with collaborative working between buyers and suppliers, joint product development, common systems and shared information". Shih, Hsu, Zhu and Balasubramanian, (2012:70) add that, in order to decrease uncertainty one needs to integrate the IT system with the supply chain network resulting in lower production costs, shorter lead 
times, and faster product delivery. The authors advocate that information sharing is suitable for efficient day-to-day operations, but when the decision-making processes become more complex and chaotic, knowledge management is better because it makes it easier to address the uncertainty and changes in the environment. As the supply chain entails multiple actors working together in a process of value creation, effective management of relationships among the actors is vital to the success of SCM (Christopher, 2011). In essence, there needs to be harmony among supply chain members - with a diverse set of cultures, structures and behaviours - in order for them to achieve the synergistic effect of working together as a team. The network theory views any system as a set of interrelated actors or nodes (Tate, Ellram \& Golgeci, 2013:266) whereby the actors can represent entities at various levels of collectivity, such as persons, firms, countries and other participants in the network (Borgatti \& Li, 2009:2). Networks represent an important way to diffuse ideas and practices among supply chain members within a network, and diffusion using network theory should enhance the collaboration in a supply chain network and is required for extended enterprises to share knowledge and skills (Rugman \& Verbeke, 1998; Tate, Ellram \& Golgeci, 2013). Although the chaos theory suggests that uncertainty in the supply chain can be managed by imposing rules or principles guided by existing knowledge and experience, electronically-enabled supply chain management systems assist in managing the flow of information and products in extended enterprise supply chain configurations.

\section{Literature review}

\section{Value of information sharing}

Information sharing is an optimisation strategy that enhances active coordination and integration in the chain network in order to address the challenges emanating from consumer DoV. Chen (2003:341) presented a comparative analysis showing that the focus has been on demand-side information, which optimises a portion of the overall flow chain network. The argument is that supply-side information shows limited retail sales information and wavering inventory at points of sale. "The manufacturers can rollover new and advanced products over an extended planning period using the solo-oriented strategy. When the periodicreview inventory system is coordinated, information sharing enhances the performance of both supply chain streams of trading partners" (Li \& Gao, 2008:522). However, the authors add that, "it is not possible to achieve embellished supply chain performance targets and benefits without proper coordination and better collaboration". Choudhury, Agarwal, Singh and Bandyopadhyay (2008:117-127) test the belief that "the benefit is increased by sharing relevant information (sharing demand and inventory information) among players in an entire supply chain". In viewing the models, balanced information sharing on both stream sites (the Chen model) and the degree of supply chain performance benefits (the $\mathrm{Li} \&$ Gao model) provide the underlying theoretical framework to address the challenges of the bullwhip effect on business operations from a profit maximisation point of view. By the same token, information sharing, a transparent retail order replenishment policy, and a reliable inventory status, lead to a reduction in inventory levels and costs (Lee \& Whang, 2000; Cheng \& Wu, 2005).

Contrarily, Chiang and Feng (2007:1429) advocate that information sharing is more beneficial for the manufacturer than for retailers in the presence of supply uncertainty and demand volatility. The value of information sharing for the manufacturer can increase or decrease with production yield variability from different cost structures and demand patterns. Li and Lin (2006:1641) have noted that the quality of the information shared may be susceptible to contextual factors, such as the type of industry, firm size, a firm's position in the supply chain, supply chain length, and type of supply chain (Chen \& Yu, 2005). In this situation, the retailer has to rely on the history of order arrivals to deduce the lead time and attempt to align replenishment decisionmaking responsibility. Information velocity is a term used to describe how fast information flows from one process to another, and information volatility is the uncertainty associated with information content, format, or timing that must be considered to add value to the supply chain (Wisner \& Stanley, 2008; Simchi-Levi et al., 2008). Wisner and Stanley (2008:316) further consider enabling information technologies as a replacement for human coordination, to reduce uncertainty, promote new synchronised coordination structures and substitute information and knowledge for inventory. These putative processes aim to simplify information flow, inventory positioning and order replenishment optimisation across supply chains. Electronically-coordinated business activities (Sebastian \& Lambert, 2003) are likely to address variance amplification through electronically-enabled supply chain management (eSCM) systems diffusion.

\section{Retail demand and risk pooling}

Expectations represent the desired level of performance (Ryding, 2011); as a result, the demand push theory of oscillation manifests greater amplification of DoV upstream from underlying responses based only on environmental stimuli (Lurkovski, 2005; Choi, Kim, Keum, Han, Ko \& Han, 2011). This phenomenon of demand variance amplification, known as the bullwhip effect, reflects a progressive increase in order (push-based) variance as order information passes upstream in a supply chain, from the customer back to the supplier level. The push-based demand variance experienced by the upper echelons has several negative implications, including the need for increased production capacity by production points and the increased capacity costs of transportation providers that result in operational instability (Chatfield \& Pritchard, 2013:159). The retail environment is changing due to increasing competition and heightened consumer expectations (Ryding, 2011). Retailers' current strategy of using advanced technology at points of sale, do not totally satisfy consumers' expectations (Pantano \& Viassose, 2012). Although the diffusion of information systems has 
transformed supply chains into supply networks, in which a number of producers, suppliers, intermediaries, and customers are globally interconnected in real time to meet and satisfy changing consumer requirements. The integration of information systems across partnering organisations has become the backbone of supply chain management as it facilitates information sharing, thereby enhancing organisational flexibility and responsiveness while minimising risk and inventory costs (Hartono, Li, Na \& Simpson 2010; Rajaguru \& Matanda, 2013).

Risk pooling assumes that the demand in the markets served by warehouses is negatively correlated (when demand at one market is greater than average, then demand at another market will be less than average) (Hopp \& Spearman, 2008). This means that the greater the positive correlation between demands, the smaller the benefit due to risk pooling (Wisner \& Stanley, 2008; Cachon \& Terwiesch, 2009). In an inverse correlated relationship, Snyder and Shen (2011:273) postulate that "the information in variability is additive in the centralised system but multiplicative in the decentralised system with shared demand information as a significant factor to reduce bullwhip effect". The underpinning view from Simchi-Levi et al. (2008) allude to the fact that "the benefit of risk pooling in a centralised system depends on the standard deviation $(\boldsymbol{\sigma})$ or the coefficient of variation $(\boldsymbol{\sigma} / \boldsymbol{\mu})$ among the different markets with support of e-SCM system". The higher the standard deviation or coefficient of variation, the greater the potential benefit from a centralised system, although the benefits of risk pooling also depend on demand correlation among the different markets. Arguably, a decentralised supply chain allows the manufacturer greater proximity to consumers with quasi-actual demand information (Simchi-Levi et al., 2008).

\section{Research methodology}

\section{Research design}

The research design outlines a plan and structural framework for how the researcher intends to conduct the study to solve the research problem (Cooper \& Schindler, 2008:140). This study used a cross-sectional quantitative approach to analyse data, and a self-administered questionnaire survey instrument was used for data collection. Organisations in retail sales, logistics, warehousing, marketing, manufacturing and information technology hubs were the units of analysis in this study. Managers (senior and functional levels) including supervisory level (non-managerial), were used as the subjects within the organisations. The supervisory positions were considered for their reliable information and comprehensive understanding of individual retail outlets as well as retail warehousing systems. It is crucially important for this study to make thoughtful and sound inferences in order to produce integrated research that yields new knowledge and solution-based findings.

\section{Data collection}

\section{Survey instruments}

A survey instrument incorporating statements on the bullwhip effect, inventory positioning, information sharing, electronically-enabled supply chain management (e-SCM) and strategic global optimisation activities was selfconstructed based on the literature reviewed. The content validity of the instrument was established by grounding it in extant literature. A questionnaire was designed by the researcher based on both the constructs of the conceptual and contextual framework using structured questions to enhance the thematic research thread objectivities. While it could be argued that objective scales are more insightful, the study used subjective scales because of the multi-sectoral nature of the survey. Sekaran and Bougie (2009:197) describe a questionnaire as an efficient data collection mechanism with a pre-formulated, written set of questions to which respondents record their answers, usually within rather closely defined alternatives. The pre-formulated thematic instrument (bullwhip effect, information sharing, inventory positioning and optimisation strategies) was grounded within the extant literature review. It was pretested using key industry practitioners and discipline-based academics for suitability in order to enhance face and content validity.

The survey questionnaire was structured into five sections with section one including typical demographic data, a personal profile and general information for both the company and individual respondents, representing nominal data (mutually exclusive and collectively exhaustive) and rank-ordered statements (ordinal data). Section two included dichotomous questions (Yes or No) on general perceptions of inventory management systems to mitigate the bullwhip effect, representing nominal data. Sections three and four included interval data with a series of statements that covered operational supply chain networks on the bullwhip effect, information sharing, electronic supply chain management integration and global optimisation strategies to ameliorate the bullwhip effect. According to Anderson (2009:312), clarity on the research questions and types of data collected should allow the researcher to identify the most appropriate quantitative data analysis tools to use on the main underlying option for parametric and/or nonparametric data (Collis \& Hussey, 2009; Cooper \& Schindler, 2008; Davies, 2007; Hair, Jr, Babin, Money \& Samouel, 2003). The last section listed numerous e-SCM systems that were being used or recommended by the respondents.

Respondents indicated the degree of agreement or disagreement, where 5 represented "strongly agree" and 1 represented "strongly disagree". In other words, multiquestion Likert-type five point scales ranging from strongly agree to neutral to strongly disagree in sections three and four were used to derive composite scores of data for each variable as representative of interval data. The respondents were assured that the researcher would not disclose the 
names of the participating firms or individual respondents to honour ethical requirements. Assurance of anonymity tends to yield greater confidence and encourage participation in a research study.

\section{Data sampling methods}

A nonprobability sample that assimilated this study's criteria with purposive sampling is called judgment sampling. Nonprobability sampling has some compelling practical advantages to meet the sampling objectives of the study (Blumberg, Cooper \& Schindler, 2008:235). This sampling occurs when a researcher selects sample members to conform to some criterion (Cooper \& Schindler, 2008: 397). It calls for special efforts to locate and gain access to individuals that possess the requisite information. Convenience sampling was identified based on the design of deliberate sampling for heterogeneity. In other words, one defines target ranks and departmental persons to ensure that a wide range of instances from within each echelon are represented. Sekaran and Bougie (2009:276) describe convenience sampling as one of the best ways to collect information quickly and efficiently from members of the population who are able to provide such information. Referral sampling also proved to be the most efficient and effective approach that eventually yielded the majority of the potential respondents on the sampling frame. Snowball sampling relies on approaching a few individuals from the relevant population; these individuals then identify other members from the same population for inclusion in the sample (Welman, Kruger \& Mitchell, 2005:69).

\section{Sampling size}

The retailers (downstream supply chain) and capacitated suppliers (mid and upstream supply chain) in the selected FMCG industry constituted the population of 800 proportionate representatives within five major retail chain stores in eThekwini Metro, South Africa. Approximately 300 selected suppliers for these retail chain stores in food (dairy, frozen, canned and general) and beverages (hot and cold), and the personal health care category were considered for this empirical research study. The sample size of 456 (260 retailers and 196 suppliers) was considered adequate as Sekaran $(2003: 295)$ notes that sample sizes of larger than 30 and less than 500 are appropriate for most research on a population-to-sample size table. According to Sekaran (2003:294) and Bartlett, Kotrlik and Higgins (2001:48), the representative population size of 800 (retailers) and 300 (suppliers) in determining minimum returned sample size is 260 and 196 sample size, respectively, with an alpha of 0.05 and a degree of accuracy of 0.05 . The alpha value or level of significance (0.05) would become enshrined as the threshold value for declaring statistical significance in this study. This study produced a sample size of 448 respondents with a return rate of $98 \%$ [(448/456) 100]. According to Krejcie and Morgan (1970), researchers typically set a sample size level of about 500 to optimally estimate a single population parameter; in turn, this will construct a $95 \%$ confidence interval with a margin of error of about $\pm 4.4 \%$ for large populations. In terms of an inverse relationship between sample size and the margin of error, smaller sample sizes will yield larger margins of error. Larger sample sizes generally lead to increased precision when estimating unknown parameters (Cooper \& Schindler, 2008; Babbie \& Mouton, 2001; Krejcie \& Morgan, 1970).

\section{Administering survey}

The questionnaire was self-administered through scheduled delivery and collection of questionnaires within the agreed time intervals to enhance the return rate. The questionnaires were delivered to individual gatekeepers to administer the survey within their domain and most questionnaires were personally administered by the researcher within the eThekwini Metro, South Africa. The relevant letters (gatekeeper's letter, ethical clearance certificate, and letter of consent to ensure confidentiality and anonymity) were shown to the gatekeepers when the researcher was given permission to enter their domain.

\section{Statistical analysis of data}

The statistical analysis aimed to achieve the study's research objectives. The summarised univariate technique examined the distribution of cases on one variable at a time using descriptive statistics (mean and standard deviation). The multivariate analysis was organised around a scheme of interdependence (factor analysis) procedures to develop models and dimensions that best describe the population as a whole.

\section{Frequency distribution: experience and perceptions of participants on three critical variables}

This figure shows three critical variables (inventory positioning, e-SCM systems and information sharing) on the experience and perceptions of the participants. The degree of agreement on the statements focuses on e-SCM systems, optimal inventory positioning and information sharing in attempting to mitigate consumer demand order variability in the supply chain network.

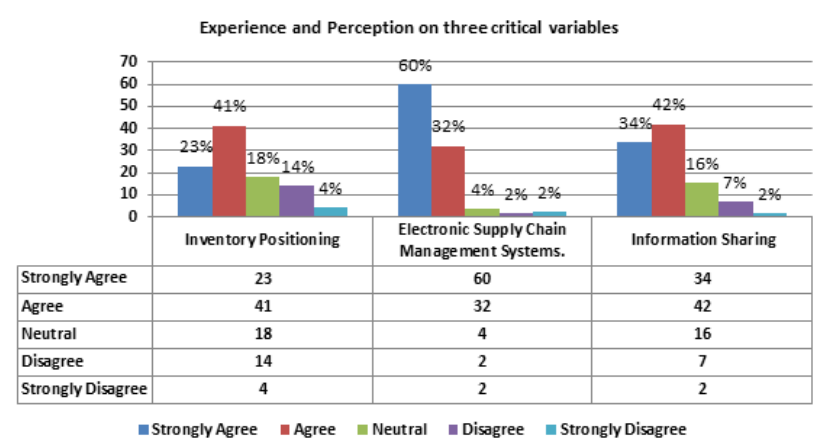

Figure 1: Experience and perception of participants on three critical variables 
The fundamental theoretical framework to analyse the challenges of the bullwhip effect on the FMCG industry is constructed around inventory positioning, information sharing and e-SCM systems. The results show that the overwhelming majority $(92 \%)$ of the respondents agree that e-SCM systems alleviate both push- and pull-based oscillating demand order variability in the supply chain network. The systems further enhance optimal inventory positioning (64\%), while achieving better coordination on quasi-real-time information sharing (76\%). These key theoretical components of this study provide considerable insight into the role of electronically enabled-SCM systems and possible mitigation mechanisms for consumer DoV. Electronic linkages between supply-side and demand-side partners indicate better information sharing communication on inventory positioning to achieve integrated supply chain management processes. The e-SCM systems have the ability to deliver rapid responses to demand variability and supply changes in order to reduce supply chain costs and the opportunity cost of lost sales. The e-SCM systems ameliorate the amplification of DoV and ultimately respond directly to pull-based consumer demand in the network.

\section{Descriptive statistics}

Measures of dispersion and central tendency provide a summary indication of the distribution of cases and an average value by describing a single variable within the exploratory study. This section of the study advocates that eSCM systems $(M=4.56)$ are the most significant systems to alleviate DoV in the FMCG industry. These systems seem to create agility and a high level of flexibility to respond rapidly to changing market requirements from diverse customers by quickly delivering the right products and services through effective integration. The e-SCM system is described as "a mechanism to integrate trading supply chain partners at technical, operational and business level with efficient real-time information sharing and active coordination" to mitigate the bullwhip effect (Ke, Lui, Wei, Gu \& Chen, 2009:839).

The semantic view of electronically-enabled supply chain management underpins the effective updated demand forecast $(\mathrm{M}=4.04$ with 0.996 std deviation) wherein organisations jointly participate in updating the demand forecast across the stream sites of a supply chain. Although the e-SCM systems are significant in improving flexibility, future strategic communication $(\mathrm{M}=3.88)$ and informal and formal information sharing $(\mathrm{M}=3.92)$ in the dynamic market, as well as information exchange $(\mathrm{M}=4.00)$, are associated with a high order fulfillment rate and a shorter order cycle time to enhance supply chain performance targets in the FMCG industry.

The integrated e-SCM systems $(\mathrm{M}=3.80)$ provide flexibility to respond ( $\mathrm{M}=3.61$ ) to emergency demand order changes despite the fact that organisations frequently hold a large inventory to avert inventory stock outs $(\mathrm{M}=$ 3.68). The respondents agree that the electronically-enabled supply chain system plays a significant role (highly ranked
$M=4.46)$ in improving willingness to share sensitive and confidential information $(\mathrm{M}=3.60)$ based on trust, and offers greater control and access to advanced economic information $(\mathrm{M}=3.66)$. Furthermore, the system will enhance profitability $(\mathrm{M}=3.70)$ and establish common goals and mutual dependency $(\mathrm{M}=3.63)$ between collaborating supply chain partners to further optimise inventory positioning $(\mathrm{M}=3.65)$ with a significant reduction in lead times $(M=3.75)$. Despite the essential role of e-SCM systems, organisations tend to order large quantities to take advantage of transport discounts $(\mathrm{M}=$ 3.85) while making a concerted effort to reduce total lead time $(M=3.67)$ in terms of material, information and delivery lead times and delays. The push-based demand without virtual approach creates price fluctuations $(\mathrm{M}=$ $3.70)$ that tend to inflate demand orders $(\mathrm{M}=3.77)$ during promotions and periods of shortage.

\section{Descriptive statistics relating to strategic optimisation}

The study found that risk pooling $(\mathrm{M}=3.90)$ is the most significant global optimising and cost-effective strategy to reduce consumer DoV by aggregating demand across locations. The consolidated distribution strategy for either lead time pooling or location pooling keeps inventory close to customers while hedging against certain forms of uncertainty. The central inventory location within a supply chain can exploit lead time pooling to provide some of the benefits of location pooling without moving inventory far away from customers. The respondents advocated the central supply chain distribution system $(\mathrm{M}=3.86)$ as a global optimisation model for individual retail facilities that enhances the integration of stock ordering, buying systems and store replenishment systems. This collaborative supply chain system focuses on directly involving suppliers to realise high levels of product availability, service levels and stock runs. Interestingly, the collaboration, planning, forecasting and replenishment (CPFR) model $(\mathrm{M}=3.74)$ with a standard deviation of 1.069 is perceived as the most important model to provide unlimited access to a retail store's replenishment system to ameliorate and manage DoV.

This model is most suitable for the build-to-order supply chain (BTOSC) system $(\mathrm{M}=3.67)$ to allow the greatest degree of order replenishment flexibility and responsiveness on the basis of market sensitivity, leveraged IT and tactical postponement agility. The BTOSC system requires the decoupling point (boundary) to describe forecast-driven and demand-driven elements with real-time information flow to achieve whole system optimisation. The demand-driven strategy, also known as a pull-based supply chain $(\mathrm{M}=$ 3.67) with standard deviation of 1.039 is the better ranked strategy to improve production leagility and coordination of customer demand and distribution. The system optimises the processes and is customer demand-driven to enhance customer satisfaction through a clear understanding of demand order variation and oscillation. The forecast-driven model with accurate forecasting $(\mathrm{M}=3.65$ and $\mathrm{SD} / \sigma=$ 
1.119 ) is supported by the respondents to control the bullwhip effect in linking the inventory positioning and order replenishment decisions among supply chain trading members. Order replenishment decisions allow the supplier managed inventory (SMI) system $(\mathrm{M}=3.64)$ with standard deviation of 1.074 "to shift responsibility for inventory planning from manufacturer to supplier" with an oriented paradigm on customer services and proximity to downstream customers.

\section{Assessment of reliability and validity}

Researchers need to ensure the measure of the right concept and measure the stability and consistency of the concept, which is determined by reliability. This study tested reliability using Cronbach's alpha, which is a test for internal consistency. Cronbach's alpha values (0.60) show construct validity and that the constructs are measured with sufficient reliability. This statistic provides an indication of the average correlation amongst all the items: reliability is achieved as Cronbach's alpha value is equal and/or greater than 0.60 (Bryman \& Bell 2007:164). Validity can be determined by applying certain validity tests in order to measure the right concept (Bryman \& Bell 2007:165). Content validity measures the adequacy of the sample (McBurney \& White 2004:129), whilst criterion validity examines the relationship between scale scores and some specified scores and construct validity measures the degree to which the scale measures the underlying concept it claims to measure (Beins \& McCarthy 2012:68).

\section{Factor analysis}

The purpose of factor analysis is to discover discrete dimensions in the pattern of relationships among the variables in the survey instrument. This study provides a reduced number of six different factors that explain the pattern of relationships among the variables. Helizer, Hollis, de Hernandez, Sanders, Roybal and van Deusen (2010:224) further stress the need to identify the nature of the factors, the relationships between the fit of the factors to the observed data, and the amount of random or unique variance of each observed variable. This statistical technique allows for the identification of a relatively small number of individual factors that can be used to represent relationships among sets of many interrelated variables (Norusis, 1993). Nevertheless, its major objective is to reduce a number of observed variables to a small number of underlying grouped factors in order to enhance interpretability and detect hidden structures in the data (Treiblmaier \& Filzmoser, 2010: 198). Fabrigar, Wegener, MacCallum and Strahan (1999:272-299) observe that this statistical technique has been extensively used in psychological research to understand aspects of human behavior from the structure of dimensional constructs, after being popularised by Charles Spearman in the early 1900s. The purpose of principal component analysis (PCA) is to derive a relatively small number of components that can account for a variability found in a relatively large number of measures (De Coster, 1998:3). This study uses principal components analysis with varimax rotation as the method for data analysis and the Kaiser criterion to decide on all factors with eigenvalues greater than one to be retained for rotation.

Table 1: Factor analysis on KMO and Bartlett's test, rotated components and Alpha

\begin{tabular}{|c|c|}
\hline KMO and Bartlett's Test & \\
\hline Kaiser-Meyer-Olkin (KMO) Measure of Sampling Adequacy & .832 \\
\hline Bartlett's Test of Sphericity & 3662.946 \\
\hline 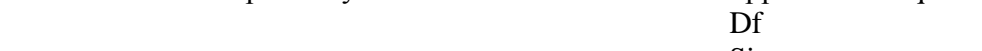 & 465 \\
\hline Sig. & .000 \\
\hline
\end{tabular}

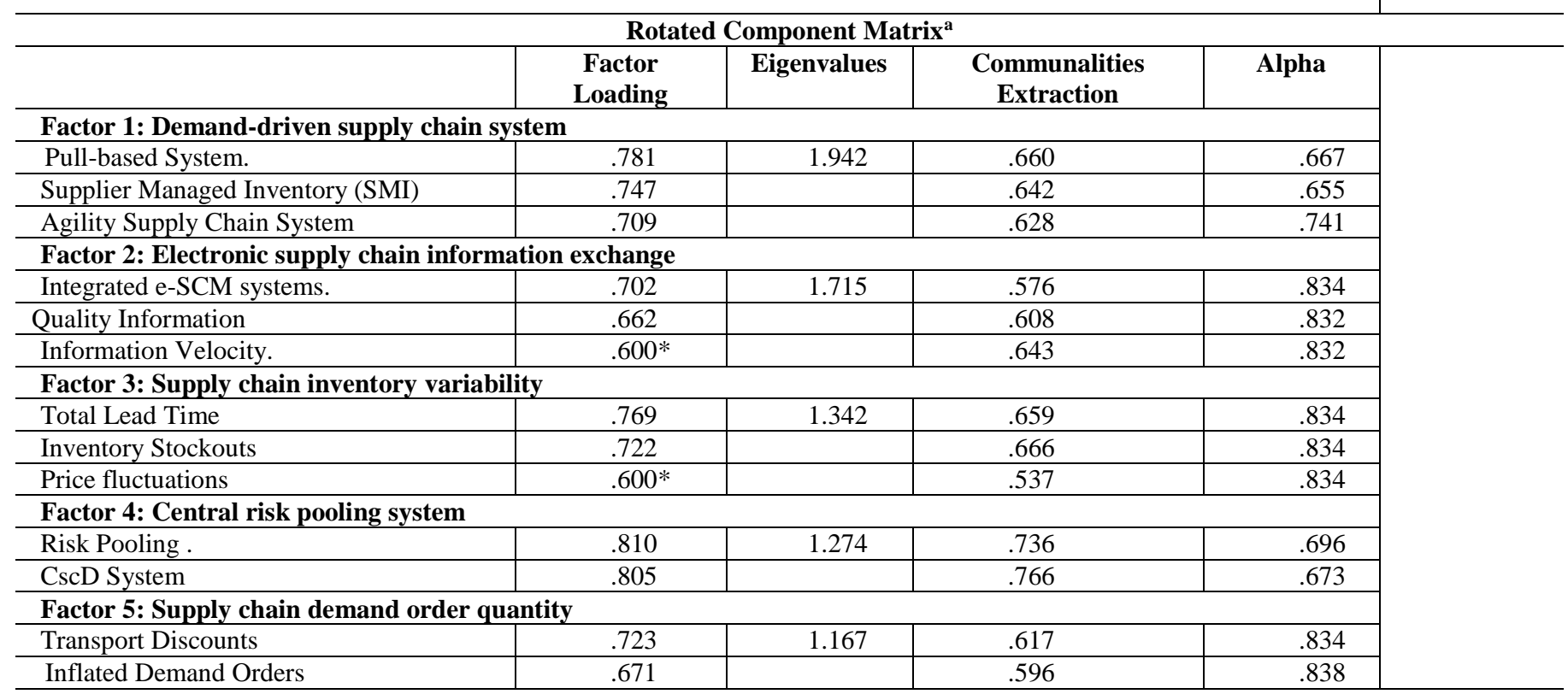




\begin{tabular}{l}
\hline Factor 6: Electronic supply chain communication system \\
\hline Strategic Communication \\
e-SCM Systems.
\end{tabular}

\section{Assumptions in factor analysis}

Factor analysis has a propensity to epitomise subjectivity in imputing factor labels from factor loadings; in the absence of a panel of neutral experts in the imputation process, factor interpretations and labels use face validity with strong rooted theory to infer from factor loadings. According to Garson (2012:55), there is near universal agreement that factor analysis is inappropriate when the sample size is below 50. This study concurs with the suggested general rule of thumb that at least 300 cases should be used for factor analysis (Tabachnick \& Fidell, 2007:613), while Sapnas and Zeller (2002) and Zeller (2005) recommend 100 or even 50 cases under some circumstances. Normality assumption pertains to the significance testing of coefficients, and factor analysis is a correlation technique, seeking to cluster variables along dimensions (Garson, 2012:59).

The construct validity was evaluated using Cronbach's Alpha reliability test while the convergent validity of the instrument was assessed by examining the factor loadings. Cronbach's Alpha values range from 0.655 to 0.842 , which implies reasonable reliability of the scales. This study generated a number of larger variables into six loaded factors with an overall value of Cronbach's alpha (0.701). The purpose is to capture as much information as possible from the original data set using an interdependence tool. This omnibus alpha value reflects good internal consistency reliability in terms of the correlations amongst the factors and the adopted measurement scales. The Bartlett test of sphericity indicated that correlations exist among the variables (measures of sampling adequacy of 0.832 , chisquare of 3662.946, degree of freedom of 465 and significant value of 0.000). By the same token, the KaiserMeyer-Olkin (KMO) test provided the measure to quantify the degree of intercorrelations among the variables and the appropriateness of the interdependence technique. Exploratory factor analysis was applied to ensure the unidimensionality of the scales. Both principal component analysis and varimax rotation in SPSS were chosen to identify the factors where the number of factors was not specified in advance. The variance explained by the combination of the six dimensions is $61.735 \%$ while the "supply chain information integration system" dimension explained the biggest part of the variance (variance = $21.071 \%$ ). In an attempt to understand how much of the total variance of all variables is covered by the factor, all six factors have eigenvalues over 1.0, which bestow more credibility on the factor analysis results.

This study developed six tacit constructs that can be transformed into explicit bullwhip effect challenges and optimal mitigation strategies. It tentatively achieved its objectives by incisively developing bullwhip effect dimensions together with efficient optimal mitigation strategies towards ameliorating DoV in the FMCG industry. The conceptual patterns depict relations between the extracted principal six bullwhip effect dimensions using the varimax rotation method and their respective subcomponents. This study developed conceptual patterns of six key new bullwhip effect dimensions that are all related to either bullwhip effect challenges or supply chain optimisation business performance outcomes.

\section{Demand-driven supply chain system}

The first dimension focuses on enriching the upstream site with customer and demand-driven inventory positioning by inducing velocity and flexibility in the supply chain to ameliorate consumer DoV. The principle of agile supply chains in particular, enhances customer satisfaction through optimum processes and customer-driven-demand from the pull-based supply chain as orders move upstream on realtime information sharing systems (Cachon \& Terwiesch, 2009; Simchi-Levi et al., 2008; Mason-Jones et al., 2000). The supplier managed inventory partnerships resemble vendor managed inventory (VMI) partnerships but the supplier takes responsibility for managing the supply chain inventory. In an integrated e-SCM system, the retailers transmit their point-of-sale data to the vendor's central hub of data to facilitate centralised control and management. The magnitude of collaboration between supply chain partners will allow supply chain coordination on production schedules, forecast demand and demand order replenishment frequencies to subdue the bullwhip effect.

\section{Electronic supply chain information exchange}

The second dimension focuses on how the attributes of clockspeed quality information sharing improve the integrated e-SCM systems for shorter order cycle times and higher order replenishment frequencies. Electronicallyenabled information exchange systems improve the quality and velocity of information sharing through reciprocal interdependence and integrated coordination both across and within firms. Chopra and Meindl (2007) and Chatfield, Kim, Harrison and Hayya (2004) suggest that IT provides the tools to gather quality information and analyse real-time information to make optimal supply chain decisions. Although this factor is underpinned by immense trust and shared vision between the supply chain partners, the industry type and the length of the supply chain tend to impede the quality of information sharing and velocity of information flow. 


\section{Supply chain inventory variability}

The third dimension focuses on how the desired service level in reducing the total lead time prevents stockouts and overcomes the effect of price adjustment mechanisms. Although the electronic point-of-sale data sharing system can reduce total lead times (Simchi-Levi et al., 2008) by expediting purchase orders and communication, the manufacturing processes and schedules indicate difficult challenges to shorten lead times (Cachon \& Terwiesch, 2009). In this regard, the desired service level to purchase and hold a large quantity of inventory in the supply chain network is required to prevent stock outs and to overcome the effect of price fluctuations during promotions.

\section{Central risk pooling system}

The fourth dimension focuses on how demand order aggregation across locations ensures on-time delivery of customer orders at desired stock levels. In other words, the central supply chain distribution systems have the potential to allow manufacturers and suppliers to orchestrate their capacity planning and demand forecast within a central pooling location, while the retailers try to ensure on-time delivery of customer orders at desirable stock level. Wanke and Saliby (2009) and Rojas (2007) consider consolidation efforts in terms of inventory centralisation, order splitting and transshipment as cornerstone tools to measure inventory costs, service levels and total costs. Risk pooling occurs because the centralised system takes advantage of the concave nature of safety stock requirements. According to Snyder and Shen (2011:146), the excess inventory at the low-demand distribution centre can be used to make up the shortfall at the high-demand distribution centre in the centralised system. If the distribution centres are consolidated into a single distribution centre, this super-hubdistribution centre serves total demand. Its mean $\left(\mu_{\mathbf{C}}=\right.$ $\left.\sum_{i=1}^{N} \mu_{i}\right)$ and standard deviation

$\left(\sigma_{C}=\sqrt{\sum_{i=1}^{N} \sum_{j=1}^{N} \sigma_{i j}}\right)$ in a centralised system show that the optimal base-stock level for the centralised system is $\boldsymbol{S}_{C}^{*}=$ $\boldsymbol{\mu}_{\boldsymbol{C}}+\boldsymbol{z}_{\propto} \boldsymbol{\sigma}_{\boldsymbol{C}}$ with optimal expected cost

$E\left[C_{C}\right]=\eta \sigma_{\mathrm{C}}=\eta \sqrt{\sum_{i=1}^{N} \sum_{j=1}^{N} \sigma_{i j}}$ where a single distribution centre system is formed by merging the distribution centres in a centralised system,

$\boldsymbol{E}\left[\mathbf{C}_{\mathbf{C}}\right] \leq \boldsymbol{E}\left[\mathbf{C}_{\mathbf{D}}\right]($ Snyder \& Shen, 2011).

\section{Supply chain demand order quantity}

The fifth dimension describes the conventional cause of the bullwhip effect when the downstream supply chain inflates demand order quantities to take advantage of transport discounts. The customers tend to accumulate a safety stock target with distorted demand signals. Wisner and Stanley (2008) cautions that, this results in "unnecessary additions to production capacity, warehouse space and transport investments". If the distorted demand order quantity for earning transport discounts does not freely allow order cancellations in a supply chain, the inflated orders and gaming behaviour strategies become major causes of the bullwhip effect.

\section{Electronic supply chain communication system}

The sixth dimension focuses on how e-SCM capabilities facilitate the communication of future strategic requirements in a supply chain to enhance demand order replenishment frequencies. The electronic system can enhance a trustbased coordination structure, better communicate demand order replenishment requirements for consistent product availability and accelerate physical product and information flow capacity.

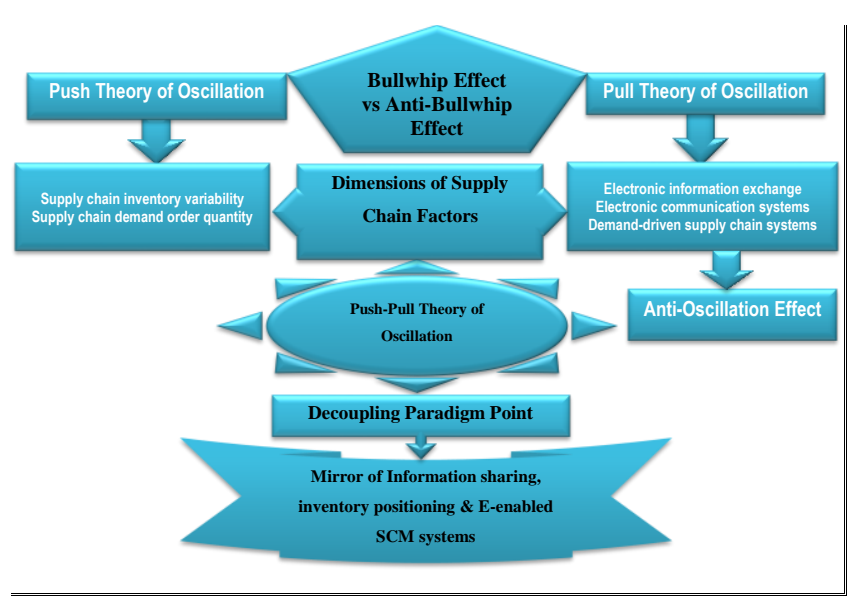

Figure 2: Push-pull theory of oscillation

Source: Developed by the researcher from the empirical study

In the push theory of oscillation, there is an amplification of DoV from the custodians of information (downstream retailers) that generate orders with distorted demand information moving upstream. In the pull theory of oscillation, the amplification of DoV is based on reactions (which all ultimately respond directly to genuine customer demand - as Anti-Oscillation Effect) from integrated e-SCM systems and synchronised processes of decision-making responsibility across extended enterprises. The study reveals that the surfaces of bullwhip and those of maximum oscillations of inventories can be obtained as the push theory of oscillation, with the weight given to the history of the demand and the importance given to the last incoming order. This means that the bullwhip and the maximum oscillation surfaces have a similar characteristic shape for all demand (supply chain inventory variability and demand order quantity). The push theory of oscillation describes the oscillating DoV that originates and germinates from the operational downstream-site of demand information distortion and disintegrated order replenishment policies within supply chain networks. It is also driven by multiple causes of the bullwhip effect, such as total lead times, inventory stockouts, price fluctuations, transport discounts 
and inflated demand orders. The pull theory of oscillation describes the oscillating DoV that is controlled and customer-to-customer driven by the innovative exploitation of integrated electronically-enabled supply chain systems, quality knowledge and information sharing, and information velocity on downstream diagnosed customer demand and upstream engineered market changes. The alleviation of DoV can be achieved through electronically-enabled supply chain central hubs for better integrated strategic communication using informal and formal information. This pull-based, innovative theory focuses on enriching upstream with consumer and demand-driven inventory positioning by inducing agility within the supply chain networks. In other words, customer satisfaction is enhanced through the optimisation process and customer driven-demand from the pull-based supply chain (Simchi-Levi et al., 2008), an understanding of demand variation, order oscillations and demand uncertainty (Jacobs \& Chase, 2008), the behaviour of supply chain partners as orders move upstream, and information sharing systems (Cachon \& Terwiesch, 2009). In this regard, the pull-based theory of oscillation initially focuses on a sysnchronised supply chain approach as supply chain sharing, in terms of both demand visibility and decision-making responsibility with suppliers that implies complete inventory and planning collaboration (Ciancimino, Cannella, Bruccoleri \& Framinan, 2012:50). Secondly, the pull-based theory of oscillation should relate to the coordination of production planning, inventory management and distribution activities across the network. The intensification of global competition and the demand for better customer service indicate the need for integration between companies in order to coordinate the processes along the supply chain (Danese, Romano \& Formentini, 2013:126).

The decoupling point also acts as a strategic point for buffer stock, and its position changes depending on the variability in demand and product mix (Mason-Jones et al., 2000). An increase in product mix and fluctuating volume would force the decoupling point to move upstream, making the supply chain system more agile to ameliorate the magnified oscillations upstream. In this study, the decoupling paradigm point assists in ameliorating order vacillation through central consolidation and a risk pooling system using the mirror of the three dimensions of information sharing, visible inventory positions and electronically-enabled supply chain systems on the viably regionalised central hubs. The decoupling point epitomises customer-driven orders on the upstream site using positive interventions to alleviate the impact of the bullwhip effect in the FMCG industry. Customers are becoming more and more aggressive in demanding new products and services within a short period of time (closespeed), and the hybrid strategies (push-pull theory) should facilitate proper understanding of the underlying causes of oscillation (the push theory of oscillation) and managing oscillation through the mirror dimensions (the pull theory of oscillation) to tame and manage consumer DoV in the supply chain. This dichotomy of oscillated demand order-push (developing silo-oriented demand orders and adapting to the changing characteristics of the industry structure) and demand order-pull has brought the juxtaposition of these two approaches to the magnitude of consumer DoV from the characteristics of supply chain networks. The demand order-pull approach requires the identification of a broader set of supply chain market features, including the characteristics of the end markets and the whole supply chain network economy that affects the performance of supply chain frequencies to demand order replenishment rate (Stefano, Gambardella \& Verona, 2012:1283). Globalisation and environmental uncertainty have increased the challenges confronting managers in delivering services or products to the customer. Dynamic environments require managers to create new value propositions that use emphatically-driven chain relationships characterised by mutual trust, value-adding propositions and correct service expectations, and product quality and quantity from organisational flexibility and responsiveness (aligned with the pull-based theory of oscillation).

\section{Managerial implications}

This study developed six tacit constructs that can be transformed into explicit bullwhip effect challenges and optimal mitigation strategies. These dimensions reflect a new perspective in managing and controlling amplification in the consumer DoV moving upstream the supply chain network. This study tentatively achieved its objective by incisively developing bullwhip effect dimensions together with efficient optimal mitigation strategies to ameliorate DoV in the FMCG industry. The conceptual patterns depicted relations between the extracted principal six bullwhip effect dimensions using the varimax rotation method and their respective sub-components. The empirical evidence in this study confirmed a number of bullwhip effect challenges and the critical role of e-SCM systems, information sharing, optimal inventory positioning and global optimisation strategies. The electronically-enabled supply chain management systems improve effective communication with efficient real-time information sharing and better coordination of supply chain processes with integrated supply chain performance to mitigate the bullwhip effect. The frequent adoption and implementation of business to business information technology (B2BIT) systems allows the migration from an in-house IT department to align technology clockspeed with a centrally integrated hub as an agile and highly flexible, responsive system to address changing market requirements.

\section{References}

Anderson, V. 2009. Research methods in human resource management. $2^{\text {nd }}$ Edition. London: Chartered Institute of Personnel Development.

Babbie, E. \& Mouton, J. 2001. The practice of social research. Cape Town: Oxford.

Bartlett, J.E., II, Kotrlik, J.W. \& Higgins, C. 2001. 'Organisational research: Determining appropriate sample size for survey research', Information Technology, Learning and Performance Journal, 19(1): 43-50. 
Beins, B.C. \& McCarthy, M.A. 2012. Research methods and statistics. Upper Saddle River: Pearson Education Inc

Blumberg, B, Cooper, D.R. \& Schindler, P.S. 2008. Business research methods. New York: McGraw-Hill International.

Borgatti, S.P. \& Li, H. 2009. 'On social network analysis in a supply chain', Journal of Supply Chain Management, 45(20): 5-22.

Bowersox, D.J., Closs, D.J., Cooper, M.B. \& Bowersox, J.C. 2013. Supply chain logistics management. $4^{\text {th }}$ Edition. Boston: McGrawHill.

Bryman, A. \& Bell, E. 2007. Business research methods. 2nd Edition. New York: Oxford University Press.

Burns, L.R. \& Wholey, D.R. 1993. 'Adoption and abandonment of matrix management programs: Effects of organisational characteristics and interorganisational networks', Academy of Management Journal, 36(1): 106-138.

Burt, D.N., Dobler, D.W. \& Starling, S.L. 2003. World class supply management: The key to supply chain management. $7^{\text {th }}$ Edition. New York: McGraw-Hill/Irwin.

Cachon, G. \& Terwiesch, C. 2009. Matching supply with demand: An introduction to operations management. Boston: McGraw-Hill Irwin.

Cai, X. \& Du, D. 2009. 'On the effects of risks pooling in supply chain management: Review and extensions', Acta Methematic Applicatae, 25(4): 709-722.

Chatfield, D.C. \& Pritchard, A.M. 2013. 'Returns and the bullwhip effect', Transportation Research Part E, 49: 159-175.

Chatfield, D.C., Kim, J.G., Harrison, T.P. \& Hayya, J.C. 2004. 'The bullwhip effect - Impact of stockastic lead time, information quality \& information sharing: A simulation study', Production \& Operations Management, 13(4): 340-353.

Chen, F. 2003. 'Information sharing and supply chain coordination', Operations Research and Management Science, (11): 341-422.

Chen, F. \& Yu, B. 2005. 'Quantifying the value of leadtime information in a single-location inventory system', Manufacturing Service Operations Management, 7(2): 144-151.

Chen, I.J. \& Paulraj, A. 2004. 'Understanding supply chain management: Critical research and a theoretical framework', International Journal of Production Research, 42(1): 131-163.

Cheng, T.C.E. \& Wu, Y.N. 2005. 'The impact of information sharing in a two-level supply chain with multiple retailers', Journal of the Operational Research Society, (56):1159-1165.

Chiang, W.K. \& Feng, Y. 2007. 'The value of information sharing in the presence of supply uncertainty and demand volatility', International Journal of Production Research, 45(6): 1429.

Choi, H.P. 2008. 'Supply chain information sharing and the impact of information errors', unpublished $P h D$ dissertation, Indiana University: USA.

Choi, W-H., Kim, S.I., Keum, M.S., Han, W., Ko, H. \& Han, D.K. 2011. 'Acoustic and visual signal based context awareness system for mobile application'. In: Proceedings of the International Conference on Consumer Electronics, IEEE, pp. 627-628.

Chopra, S. \& Meindl, P. 2007. Supply chain management: Strategy, planning and operations. $3^{\text {rd }}$ Edition. New Jersey: Pearson International.

Choudhury, B., Agarwal, Y.K., Singh, K.N. \& Bandyopadhyay, D.K. 2008. 'Value of information in a capacitated supply chain', INFOR, 46(2): 117-127.

Christopher, M. 2011. Logistics and supply chain management. $4^{\text {th }}$ Edition. Boston: Pearson Publishing.

Ciancimino, E., Cannella, S., Bruccoleri, M. \& Framinan, J.M. 2012. 'On the bullwhip avoidance phase: The synchronised supply chain', European Journal of Operational Research, 22(1): 49-63.

Collis, J. \& Hussey, R. 2009. Business research: A practical guide for undergraduate students. Basingstoke: Palgrave.

Cooper, B.R. \& Schindler, P.S. 2008. Business research methods. $10^{\text {th }}$ Edition. New York: McGraw-Hill International.

Coyle, J.J., Langley Jr, C.J., Novack, R.A. \& Gibson, B.J. 2013. Managing supply chain: A logistics Approach. $9^{\text {th }}$ Edition. New York: South-Western, Cengage Learning.

Danese, P., Romano, P. \& Formentini, M. 2013. 'The impact of supply chain integration on responsiveness: The moderating effect of using an international supplier network', Transportation Research Part E, (49): 126-140.

Davies, M.B. 2007. Doing a successful research project using qualitative methods. Basingstoke: Palgrave MacMillan.

Ding, X. \& Gan, X. 2009. System dynamics model to analysis oscillation and amplification in the closed-loop supply chain. International Conference on Management of e-Commerce and eGovernment', IEEE, Computer Society.

Fabrigar, J.M., Wegener, D.T., MacCallum, R.C. \& Strahan, E.J. 1999. 'Evaluating the use of exploratory factor analysis in psychological research', Psychological Methods, 4(3): 272-299.

Frohlich, M.T. \& Westbrook, R. 2001. 'Arcs of integration: An international study of supply chain strategies', Journal of Operations Management. 19(2): 186-200.

Gambardella, A. \& McGahan, A.M. 2010. 'Business-model innovation: General purpose technologies and their implications for industry architecture', Long Range Planning, 43(2/3): 267-271.

Ganesan, S., George, M., Jap, S., Palmatier, R.W. \& Weitz, B. 2009. 'Supply chain management and retailer performance: Emerging trends, issues, and implications for research and practice', Journal of Retailing, 85(1): 84-94.

Garson, G.D. 2012. Factor analysis. North Carolina: Statistical Associates Publishing.

Hair, Jr, J.F., Babin, B, Money, A.H., \& Samouel, P. 2003. Essentials of business research methods. New York: John Wiley \& Sons, Inc.

Hambrick, D.C. \& Fredrickson, J. 2005. 'Are you sure you have a sStrategy?', Academy of Management Executive, 19(4): 51-62. 
Hartono, E., Li, X., Na, K. \& Simpson, J. 2010. 'The role of the quality of shared information in interorganisational systems use', International Journal of Information Management, 30(5): 399-407.

Heizer, J. \& Render, B. 2011. Principles of operations management. $8^{\text {th }}$ Edition. New Jersey: Pearson Education.

Helizer, D., Hollis, C., de Hernandez, B.U., Sanders, M., Roybal, S. \& van Deusen, I. 2010. 'Evaluation for community-based programs: The integration of logic models and factor analysis', Evaluation and Program Planning, (33): 223-233.

Hopp, W.J. \& Spearman, M.L. 2008. Factory physics. $3^{\text {rd }}$ Edition. Boston: McGraw-Hill International Edition.

Hornor, M.S. 1998. Diffusion of innovation theory, [online] <http://www.disciplewalk.com /files/Marianne_S_ Hornor.pdf>. [Accessed: 20 December 2010].

Hornor, S.H. 2008. Diffusion of Innovation Theory, [online], http://www.disciplewalk.com files/Marianne_S_Hornor.pdf.

[Accessed: 19 June 2014].

Ifinedo, P. 2011. 'Internet/e-business technologies acceptance in Canada's SMEs: An exploratory investigation', Internet Research, 21(3): 255-281.

Jacobs, F.R., \& Chase, R.B. 2008. Operations and Supply management: The Core. $2^{\text {nd }}$ Edition, Boston: McGraw-Hill.

Ke, W., Liu, H., Wei, K.K., Gu, J. \& Chen, H. 2009. 'How do mediated and non-mediated power effect electronic supply chain management system adoption? The mediating effects of trust and institutional pressures'. Decision Support Systems, 46:839-851.

Krejcie, R.V \& Morgan, D.W. 1970. 'Determining sample size for research activities', Educational and Psychological Measurement, (30): 607-610.

Lee, H. \& Whang, W. 2000. 'Information sharing in a supply chain', International Journal of Technology Management, 20(3/4), 373-87.

Lee, J. \& Kim, Y. 1999. 'Effect of partnership quality on IS outsourcing: Conceptual framework and empirical validation', Journal of Management Information Systems, 15(4): 26-61.

Li, Z. \& Gao, L. 2008. 'The effects of sharing upstream information on product rollover', Production and Operations Management Society, 17(5): 522-531.

Lin, F.R. \& Lin, Y.Y. 2006. 'Integrating multi-agent negotiation to resolve constraints in fulfilling supply chain orders', Electronic Commerce Research and Applications, 5(4): 313-322.

Lin, H. \& Huang, N. 2012. 'Understanding the determinants of electronic supply chain management diffusion'. Business and Information, E: 162-178.

Mason-Jones, R, Naylor, B \& Towill, D.R. 2000. 'Engineering the leagile supply chain', International Journal of Agile Management Systems, 2(1): 54-61.

McBurney, D.H. \& White, T.L. 2004. Research methods. $6^{\text {th }}$ Edition. Belmont: Thomson Wadsworth.

McBurney, D.H. \& White, T.L. 2007. Research methods. $7^{\text {th }}$ Edition. Belmont: Thomson Wadsworth.
Migiro, S.O. \& Ambe, I.M. 2008. 'Evaluation of the implementation of public sector supply chain management and challenges: A case of study of the central district municipality, North West Province, South Africa', African Journal of Business Management, 2(12): 230-242.

Miragliotta, G. 2006. 'Layers and mechanisms: A new taxonomy for the bullwhip effect', International Journal of Production Economics, (104): 365-381.

Newbert, S.L. 2007. 'Empirical research on the resource-based view of the firm: An assessment and suggestions for future research', Strategic Management Journal, 30(8): 909-920.

Norusis, M.J. 2012. IBM SPSS statistics 19 statistical procedures companion. Upper Saddle River, New York: Prentice Hall.

Oliveira, T. \& Martins, M.F. 2010. 'Understanding e-business adoption across industries in European countries', Industrial Management and Data Systems, 110(9): 1337-1354.

Oliveira, T., Thomas, M. \& Espadanal, M. 2014. 'Assessing the determinants of cloud computing adoption: An analysis of the manufacturing and services sectors', Information and Management, 51: 497-510.

Ouyang, Y. 2007. 'The effect of information sharing on supply chain stability and the bullwhip effect', European Journal of Operational Research, (182): 1107-1121.

Pantano, E. \& Di Pietro, L. 2012. 'Understanding consumer's acceptance of technology-based innovations in retailing', Journal of Technology Management and Innovation, 7(4): 1-19.

Pride, W.M. \& Ferrell, O.C. 2009. Marketing foundations. $3^{\text {rd }}$ Edition. Australia: Cengage Learning.

Rajaguru, R. \& Matanda, M.J. 2013. 'Effects of interorganisational compatibility on supply chain capabilities: Exploring the mediating role of inter-organisational information systems (IOIS) integration', Industrial Marketing Management, 42: 620-632.

Rangaswamy, A \& Gupta, S. 1999. Innovation Adoption And diffusion In The Digital Environment: Some Research Opportunities [online], available: http://www.google.co.za/url? $\mathrm{sa}=\mathrm{t} \& \mathrm{rct}=\mathrm{j} \& \mathrm{q}=\& \mathrm{esrc}=\mathrm{s} \&$ frm $=1 \&$ source $=$ web $\& \mathrm{~cd}=4 \& \mathrm{ved}=0 \mathrm{CEE}$ QFjAD\&url=http $\% 3 \mathrm{~A} \% 2 \mathrm{~F} \% 2 \mathrm{Fwww}$. researchgate.net $\% 2 \mathrm{Fpublicat}$ ion\%2F228587652_4._INNOVATION_ADOPTION_AND_DIFF USION_IN_THE_DIGITAL_ENVIRONMENT_SOME_RESEAR CH_OPPORTUNITIES\%2Ffile\%2F60b7d516d5156dcd08.pdf\&ei $=\mathrm{DMOzUpK} 8 \mathrm{fQ} 7 \mathrm{AbuuICgBw} \& u s g=A F Q j C N G x J t o e M o K R h 65 \mathrm{R}$ QdA3nSfxePbcbQ [2 July 2014]

Rogers, E. 1962. Diffusion of innovations. Fifth edition. [online] http://www.amazon.com/gp/reader/0029266718/ref=sib_dp_pt\# reader-link. [Accessed: 12 October 2008].

Rogers, E.M. 2003. Diffusion of innovation. $5^{\text {th }}$ Edition. New York: Free Press.

Rojas, E. 2007. 'MCS observers on board at-sea transshipment vessels', APO Mail Buoy, 10(3): 8-9.

Rugman, A.M. \& Verbeke, A. 1998. 'Corporate strategies and environmental regulations: an organising framework', Strategic Management Journal, 19(4): 363-375. 
Ryding, D. 2011. 'A comparative analysis of the relative importance of service quality for two UK grocery retailers', Journal Food Products Marketing, 17(5): 503-517.

Sapnas, K.G. \& Zeller, R.A. 2002. 'Minimising sample size when using exploratory factor analysis for measurements', Journal of Nursing Measurement, 10(2): 135-153.

Schoenherr, T. \& Swink, M. 2012. 'Revisiting the arcs of integration: Cross-validations and extensions', Journal of Operations Management, 30(1-2): 99-115.

Schroeder, R.G. 2008. Operations management: Contemporary concepts and cases. $4^{\text {th }}$ Edition. Boston: McGraw-Hill International Edition.

Sebastian, J.G.D. \& Lambert, D.M. 2003. 'Internet-enabled coordination in the supply chain', Industrial Marketing Management, 32(2): 251-263.

Sekaran, U. 2003. Research methods for business: A skill building approach. $4^{\text {th }}$ Edition. New York: John Wiley \& Sons Inc.

Sekaran, U. \& Bougie, R. 2009. Research methods for business: A skill building approach. 5th Edition. New York: Wiley \& Sons.

Shane, S.A. 2014. Technology strategy for managers and entrepreneurs. $1^{\text {st }}$ Edition. New Jersey: Pearson Publishing.

Shih, S.C., Hsu, S.H.Y., Zhu, Z. \& Balasubramanian, S.K. 2012. 'Knowledge sharing - A key role in the downstream supply chain', Information \& Management, 49: 70-80

Simchi-Levi, D., Kaminsky, P. \& Simchi-Levi, E. 2008. Designing and managing in supply chain: Concepts, strategies \& case studies. $3^{\text {rd }}$ Edition. New York: McGraw-Hill/Irwin.

Snyder, L.V. \& Shen, Z.M. 2011. Fundamentals of supply chain rheory. New Jersey: John Wiley \& Sons, Inc.

Sorescu, A., Frambach, R.T., Singh, J., Rangaswamy, A. \& Bridges, C. 2011. 'Innovations in retail business models', Journal of Retailing, 87S (1): S3-S16.

Stefano Di, G., Gambardella, A. \& Verona, G. 2012. 'Technology push and demand pull perspectives in innovation studies: Current findings and future research directions', Research Policy, (41): 1283-1295.

Tabachnick, B.G. \& Fidell, L.S. 2007. Using multivariate statistics. $5^{\text {th }}$ Edition. Boston: Pearson International Edition.

Tarofder, A.K., Marthandan, G. \& Haque, A. 2010. 'Critical factors for diffusion of web technologies for supply chain management functions: Malaysian perspective', European Journal of Social Sciences, 12(3): 490-505.

Tate, W.L., Ellram, L.M. \& Golgeci, I. 2013. 'Diffusion of environmental business practices: A network approach', Journal of Purchasing \& Supply Management, 19: 264-275.

Teece, D, Pisano, G. \& Shuen, A. 1997. 'Dynamic capabilities and strategic management', Strategic Management Journal, 18(7): 509533.

Teece, D.J. 2007. 'Explicating dynamic capabilities: The nature and micro foundations of (sustainable) enterprise performance', Strategic Management Journal, 28(13): 1319-1350.

Teece. D.J. 2010. 'Business models, business strategy and innovation', Long Range Planning, 43(2/3): 172-194.
Tidd, J. \& Bessant, J. 2011. Managing innovation: Integrating technological, market and organisational change. $4^{\text {th }}$ Edition. West Sussex: John Wiley \& Sons Ltd.

Towill, D.R. 1997. 'Forridge - principles of good material flow', Production Planning and Control, 8(7): 622-32.

Treiblmaier, H. \& Filzmozer, P. 2010. 'Exploratory factor analysis: How robust models support the detection of hidden multivariate data structures in IS research', Information and Management, (47): 197-207.

Wanke, P.F. \& Saliby, E. 2009. 'Consolidation effects: Whether and how inventories should be pooled', Transportation Research Part E, (45): 678-692.

Warburton, R.D.H. 2004. 'Analytical investigation of the bullwhip effect', International Journal of Production Management, New York: The Free Press.

Warburton, R.D.H., Hodgson, J.P.E, \& Kim, Y.K. 2004. An analytical investigation of the bullwhip effect NTC S03-MD13s. NTC Project: S03-MD13s. National Textile Center Annual Report: November 2004.

Welman, J.C., Kruger, S.J. \& Mitchell, B.C. 2005. Research methodology. $3^{\text {rd }}$ Edition. Cape Town: Oxford University Press Southern Africa.

Williams, B.D., Roh, J., Tokar, T. \& Swink, M. 2013. 'Leveraging supply chain visibility for responsiveness: The moderating role of internal integration', Journal of Operations Management, 31: 543554.

Wisner, J.D. \& Stanley, L.L. 2008. Process management: Creating value along the supply chain, text and cases. Australia: Thomson South-Western.

Wu, D.Y. \& Katok, E. 2006. 'Learning, communication, and the bullwhip effect', Journal of Operations Management, (24): 839850 .

Wu, I-L. \& Chuang, C-H. 2009. 'Analysing contextual antecedents for the stage-based diffusion of electronic supply chain management', Electronic Commerce Research and Applications, 8(6): 302-314.

Yao, Y., Palmer, J. \& Dresner, M. 2007. 'An interorganisational perspective on the use of electronically-enabled supply chains', Decision Support Systems, 43(3): 884-896.

Yeh, Y. 2005. 'Identification of factors affecting continuity of cooperative electronic supply chain relationships: Empirical case of the Taiwanese motor industry', Supply Chain Management: An International Journal, 10(4): 327-335.

Zeller, R.A. 2005. 'How few cases is enough to do a credible factor analysis?', A Monte Carlo Simulation. Manuscript submitted for publication.

Zott, C. \& Amit, R. 2010. 'Business model design: An activity system perspective', Long Range Planning, 43(2/3), 216-2. 